\title{
Renal Arteriovenous Malformation
}

National Cancer Institute

\section{Source}

National Cancer Institute. Renal Arteriovenous Malformation. NCI Thesaurus. Code C35477.

An abnormal connection between arteries and veins, occurring within the renal vasculature, which can result in flank pain, and hematuria. 